\title{
Optimizing the HRP-2 in vitro malaria drug susceptibility assay using a reference clone to improve comparisons of Plasmodium falciparum field isolates
}

Wiriya Rutvisuttinunt ${ }^{1+}$, Suwanna Chaorattanakawee ${ }^{1 \dagger}$, Stuart D Tyner ${ }^{1}$, Paktiya Teja-isavadharm ${ }^{1}$, Youry Se ${ }^{1}$, Kritsanai Yingyuen', Panjaporn Chaichana', Delia Bethell', Douglas S Walsh', Chanthap Lon', Mark Fukuda², Duong Socheat ${ }^{3}$, Harald Noedl ${ }^{4}$, Kurt Schaecher ${ }^{1}$ and David L Saunders ${ }^{1 *}$

\begin{abstract}
Background: Apparent emerging artemisinin-resistant Plasmodium falciparum malaria in Southeast Asia requires development of practical tools to monitor for resistant parasites. Although in vitro anti-malarial susceptibility tests are widely used, uncertainties remain regarding interpretation of $P$. falciparum field isolate values.

Methods: Performance parameters of the W2 P. falciparum clone (considered artemisinin "sensitive") were evaluated as a reference for the HRP-2 immediate ex vivo assay. Variability in W2 IC $C_{50}$ S was assessed, including intra- and inter-assay variability among and between technicians in multiple experiments, over five freeze-thaw cycles, over five months of continuous culture, and before and after transport of drug-coated plates to remote field sites. Nominal drug plate concentrations of artesunate (AS) and dihydroartemisinin (DHA) were verified by LC-MS analysis. Plasmodium falciparum field isolate $\mathrm{IC}_{50} \mathrm{~S}$ for DHA from subjects in an artemisinin-resistant area in Cambodia were compared with W2 susceptibility.
\end{abstract}

Results: Plate drug concentrations and day-to-day technical assay performance among technicians were important sources of variability for $\mathrm{W}_{2} \mathrm{IC}_{50} \mathrm{~S}$ within and between assays. Freeze-thaw cycles, long-term continuous culture, and transport to and from remote sites had less influence. Despite variability in W2 susceptibility, the median $\mathrm{IC}_{50} \mathrm{~S}$ for DHA for Cambodian field isolates were higher $(p<0.0001)$ than the W2 clone $(3.9 \mathrm{nM})$, both for subjects with expected (less than 72 hours; $6.3 \mathrm{nM}$ ) and prolonged (greater or equal to 72 hours; $9.6 \mathrm{nM}$ ) parasite clearance times during treatment with artesunate monotherapy.

Conclusion: The W2 reference clone improved the interpretability of field isolate susceptibility from the immediate ex vivo HRP-2 assay from areas of artemisinin resistance. Methods to increase the reproducibility of plate coating may improve overall assay interpretability and utility.

Keywords: Malaria, Plasmodium falciparum, HRP-2, ELISA, Anti-malarial drugs, Drug resistance, Drug susceptibility test

\footnotetext{
* Correspondence: david.saunders@afrims.org

${ }^{\dagger}$ Equal contributors

'Department of Immunology and Medicine, US Army Medical Corps, Armed

Forces Research Institute of Medical Sciences (USAMC-AFRIMS), Bangkok,

Thailand

Full list of author information is available at the end of the article
} 


\section{Background}

Artemisinins are the latest class of safe, effective antimalarial drugs to be threatened by drug resistance $[1,2]$. Assessment of artemisinin therapeutic efficacy is essential for health policy decision making for malaria control programmes, but an operational definition of artemisinin resistance remains elusive. In vitro/ex vivo parasite drug susceptibility tests are widely used, but uncertainties remain regarding the use and interpretation of such systems to evaluate field isolates for artemisinin resistance, particularly when used in isolation, without clinical correlation. The most commonly used in vitro/ ex vivo susceptibility assays, including histidine-rich protein 2 enzyme linked immunosorbent assay (HRP-2 ELISA) [3,4], schizont maturation [3,5], radioisotopic uptake [6,7], and most recently the SYBR Green I method [8-11], are subject to numerous sources of variability. Differences in assay methods, laboratory conditions, parasite strain susceptibility phenotypes, and technical performance can confound interpretation and affect comparability of results [12-14], especially across different laboratories. In addition, drug properties, including solubility and mechanism of action can have method-dependent effects on data analysis and interpretation [15].

The need for harmonized in vitro/ex vivo drug susceptibility monitoring to be employed by a network of regional reference laboratories has been well articulated [13]. A key recommendation supporting this effort is the use of standardized Plasmodium falciparum reference clones to provide context for variability among the several assay systems. Quantifying inherent assay variability and establishing a drug susceptibility reference range are essential for laboratory-adapted clones to permit meaningful data comparisons. Just as in clinical laboratories, establishing reference ranges can account for local variance attributable to technical performance and methodology issues. Reference ranges can then be used to classify susceptibilities of $P$. falciparum field isolates obtained from different laboratories.

Since 2004, AFRIMS has used an HRP-2 ELISA method for drug resistance testing because of its high sensitivity, particularly for the artemisinins, when used in immediate ex vivo assays of P. falciparum field isolates from low-transmission endemic areas, such as Thailand and Cambodia [3,16]. AFRIMS selected the "Indochina" W2 clone as a reference for its genetic similarity to potential field isolates, its drug susceptibility profile, and ease of culture adaptation.

W2 drug susceptibility was measured by $50 \%$ inhibitory concentrations $\left(\mathrm{IC}_{50}\right)$ against dihydroartemisinin (DHA) and artesunate (AS), as well as key long-acting agents, including mefloquine (MQ) and chloroquine (CQ), which were used as drug susceptible and resistant controls respectively. Experiments were conducted to systematically assess potential sources of assay variability. Variations in $\mathrm{IC}_{50} \mathrm{~S}$ were quantified, and the susceptible ranges of W2 for DHA and AS were established in the HRP-2 assay. The susceptibility range for W2 clones used as quality controls was also compared against $P$. falciparum field isolates from an area of suspected artemisinin resistance in western Cambodia [17].

\section{Methods}

\section{Plasmodium falciparum W2 clone cultivation}

Plasmodium falciparum reference clone W2, maintained in culture continuously at AFRIMS and cryopreserved in a glycerolyte solution, was recovered as previously described [18]. Continuous cultures were grown using a modified Trager and Jensen method [19]. Briefly, parasites were maintained in RPMI-1640 medium containing $25 \mathrm{mM}$ HEPES, $25 \mathrm{mM}$ sodium bicarbonate, 5\% human $\mathrm{O}^{+}$erythrocytes, $10 \%$ pooled $\mathrm{AB}^{+}$serum and $0.1 \mathrm{mg} / \mathrm{mL}$ gentamycin at $37^{\circ} \mathrm{C}$ with $5 \% \mathrm{CO}_{2}, 5 \% \mathrm{O}_{2}$, and $90 \% \mathrm{~N}_{2}$. Human erythrocyte and pooled serum were obtained from the National Blood Center, Thai Red Cross Society. Parasites were synchronized utilizing 5\% D-sorbitol as previously described [20]. Two sorbitol treatments were performed with a 64-hour interval to provide the highest proportion of synchronized parasites, and parasite culture was maintained for 48 hours after synchronization prior to conducting the drug susceptibility assay.

\section{Preparation of drug-coated plates}

Anti-malarial drugs were coated onto 96-well plates in triplicate to assess W2 clone variability, with the exception of the drug stability and field isolate experiments where duplicate wells were used. Drug compounds were dissolved in $70 \%$ ethanol to make $1 \mathrm{mg} / \mathrm{ml}$ stock solutions, and then diluted to appropriate concentration by sterile distilled water. Three-fold serial drug dilutions were performed on plates which then air-dried overnight in a biosafety cabinet to reach final nominal drug concentrations (after $200 \mu \mathrm{L}$ of sample were added) ranging from 20 to $0.027 \mathrm{ng} / \mathrm{ml}$ for DHA and AS, 200 to $0.274 \mathrm{ng} / \mathrm{ml}$ for $\mathrm{MQ}$ and 2,000 to $2.74 \mathrm{ng} / \mathrm{ml}$ for CQ. The top row of each plate served as a drug-free control. Molecular weight of DHA, AS, MQ $(\mathrm{HCl})$ and CQ $\left(2 \mathrm{H}_{3} \mathrm{PO}_{4}\right)$ were $284.35,384.42,414.78$, and $515.92 \mathrm{~g} /$ mole, respectively. Dried plates were stored at $4^{\circ} \mathrm{C}$. Plates were used within 2 months of preparation. Plate preparation and storage methodology was based on preliminary experiments establishing reproducibility of $\mathrm{IC}_{50} \mathrm{~s}$ under these conditions.

\section{Analysis of plate drug concentration by LC/MS}

Drug substance from the starting wells of three lots of three dry drug-coated plates selected for quality control 
analysis was recovered to determine accuracy of the nominal starting concentration of 4 ng of AS or DHA in each well. The solvent for AS and DHA used for LC/MS analysis ( $100 \mu \mathrm{L}$ of $50 \%$ acetonitrile) was added to each starting well to obtain a final concentration $40 \mathrm{ng} / \mathrm{ml}$ for both AS and DHA. The coated drug was dissolved in the solution by manually agitating the plate for $5 \mathrm{~min}$ with complete dissolution. The resulting solution was then transferred to an auto-sampler vial for LC/MS analysis, and $5 \mu \mathrm{L}$ of the solution was injected directly into the system for quantification.

Plate drug concentrations for AS and DHA for different coated plates lots were verified by LC/MS analysis using a previously described bio-analytical method [21]. Briefly, AS and DHA were analysed using the LC/MS system consisting of a reversed phase column (XTerra MS C18, $3.5 \mu \mathrm{m}, 2.1 \times 50 \mathrm{~mm}$, Waters Corporation, MA, USA) and pre-column of the same material (2.1 $\mathrm{x}$ $10 \mathrm{~mm}$ ) connected to the Alliance 2695 Liquid Chromatography system equipped with a single quadrupole Micromass ZQ (MM1) Mass Spectrometry detector (Waters Corporation) in the positive electrospray ionization mode and single ion recording. The analytes (AS and DHA) were eluted from the column with $6.25 \mathrm{mM}$ ammonium acetate buffer $\mathrm{pH} 4.5$ and acetonitrile gradient from $20 \%$ to $40 \%$ in $9 \mathrm{~min}$ at the flow rate of $0.4 \mathrm{ml} / \mathrm{min}$. The ammonium-adducts of DHA and AS were detected at the $\mathrm{m} / \mathrm{z}$ ratios of 302 and 402 and eluted near 5 and $6 \mathrm{~min}$, respectively, with total analysis time of $12 \mathrm{~min}$. Resulting concentrations were extrapolated from a standard curve of DHA or AS respectively.

\section{HRP-2 ELISA drug susceptibility testing}

Synchronized W2 parasites with $>90 \%$ ring forms were diluted to $0.5 \%$ parasitaemia with $1.5 \%$ haematocrit in 0.5\% Albumax RPMI-1640, and transferred to drugcoated plates. Plates were incubated at $37^{\circ} \mathrm{C}$ with $5 \%$ $\mathrm{CO}_{2}, 5 \% \mathrm{O}_{2}$, and $90 \% \mathrm{~N}_{2}$ for 72 hours. For field isolates, blood samples with $\leq 0.5 \%$ parasitaemia were transferred to drug-coated plates without culture adaptation (ex vivo), and those with $>0.5 \%$ parasitaemia were diluted to $0.2-0.5 \%$ before transferring. Plates were incubated at $37^{\circ} \mathrm{C}$ using a candle jar, instead of mixed gas, to create favourable conditions, and parasite growth inhibition after 72 hours was analysed by HRP-2 ELISA assay, as previously described [3].

Due to the high sensitivity of the HRP-2 ELISA assay, in order to obtain $\mathrm{IC}_{50}$ values, samples were diluted before performing the ELISA. To estimate parasite growth rate, samples were collected from the untreated wells at $0,24,48$ and 72 hours, then serially diluted and analysed by HRP-2 ELISA assay. The serial dilution providing the greatest increase in OD values between 0 and 72 hours was then used as the dilution factor for the parasite culture samples in the HRP-2 ELISA. HRP-2 protein ODs were plotted against drug concentrations and $\mathrm{IC}_{50} \mathrm{~S}$ were analysed using ICEstimator 1.2 by non-linear regression, to estimate the sigmoidal dose response curve as previously described [22,23]. For the purposes of analysing sources of variability in the W2 clone experiment (with the exception of the drug stability experiment), three individual $\mathrm{IC}_{50}$ values were estimated from each of the triplicate serial drug dilutions on the plate, while $\mathrm{IC}_{50}$ values from field isolates and the drug stability experiment were calculated by averaging ODs from duplicate serial dilutions.

\section{Assessment of sources of assay variability}

In vitro drug susceptibility testing of the W2 parasite was conducted systematically in order to determine variability of the following factors: (1) variability within an HRP-2 assay found between wells of drug plates and between different drug plates run by a single technician on a single day ('Intra-assay' variability); (2) variability between assays conducted on five different days by the same technician ('Inter-assay'); (3) Technician performance assessed as the variability between technicians in overall median $\mathrm{IC}_{50}$ values; (4) variability introduced by repeated parasite freeze/thaw cycles; (5) variability due to long-term parasite culture (Longevity); and, (6) Stability of drug-coated plates during transport to/from and storage at field sites, assessed as difference in $\mathrm{IC}_{50} \mathrm{~S}$ analysed on drug-coated plates before and after transport to field sites. During transport to and from the field sites, plates were stored on ice packs $\left(2-6^{\circ} \mathrm{C}\right)$ en route, with an average of eight hours transport time, and stored in a refrigerator $\left(2-6^{\circ} \mathrm{C}\right)$ at the field site.

\section{Comparative drug susceptibility of W2, 3D7 and D6 clones}

In order to establish comparability with previous published reports of parasite clone susceptibility phenotypes, in vitro susceptibility results for W2, 3D7 and D6 against DHA, AS, MQ and CQ (eight replicates each) were compared.

\section{Artemisinin susceptibility of field Plasmodium falciparum isolates against reference $\mathbf{W} 2$ clone}

Clinical isolates were obtained from patients enrolling in a previously reported clinical trial of artesunate monotherapy in Tasanh, Cambodia [17]. Immediate ex vivo (IEV) drug susceptibility testing without culture adaptation was performed on 125 evaluable $P$. falciparum isolates from an area of known artemisinin resistance using the methods above. Isolates were considered evaluable if an $\mathrm{IC}_{50}$ could be determined using the IEV method. In each 12-plate coating lot used for field parasite analysis, 
two to seven drug plates were randomly selected for W2 drug susceptibility testing either before or after transport to field. IEV $\mathrm{IC}_{50}$ values of field isolates were compared with $\mathrm{W} 2 \mathrm{IC}_{50}$ values.

\section{Statistical analysis}

Geometric mean, median, range and interquartile values, and\% $\mathrm{CV}$ for $\mathrm{IC}_{50}$ values were calculated. To define the normal susceptible performance range of W2 for DHA and $\mathrm{AS}$, outlier $\mathrm{IC}_{50}$ values, as determined by Grubbs' test, were excluded and the range of minimum and maximum $\mathrm{IC}_{50}$ values were defined. Kruskal-Wallis and MannWhitney $U$ tests were used to analyse the differences in technician performance and compare the $\mathrm{IC}_{50}$ values of the W2 clone to field parasite isolates. To assess drug stability, the Wilcoxon matched-pair test was used to compare $\mathrm{W} 2 \mathrm{IC}_{50}$ values on drug-coated plates before and after transport to field sites. Statistical significance was defined as $p<0.05$. For multiple comparison analysis, the cut-off $p$-value was adjusted for the number of comparisons by using the Bonferroni correction. Statistical analysis was performed using Graphpad Prism for Windows, version 5 (Graphpad Software, Inc, San Diego, CA, USA).

\section{Results}

\section{Assessment of sources of assay variability}

Three technicians performed $\mathrm{IC}_{50}$ assays on the W2 clone concurrently using triplicate serial dilutions on five different plates for each drug assayed to obtain 15 individual $\mathrm{IC}_{50}$ values (Figure 1). The\% CV for "intra-assay" variability from these individual experiments was consistent between technicians, ranging from 8.2\%-10.9\% for DHA (Figure 1) and 8.0\%-15.9\% for AS.

Each technician repeated this experiment on a total of five occasions to assess the day-to-day variability of $\mathrm{IC}_{50}$ values (inter-assay variability). The $\% \mathrm{CV}$ values for interassay variability ranged from $16.9 \%$ to $22.8 \%$ for DHA (Figure 1) and $32.3 \%$ to $36.1 \%$ for AS. Median $\mathrm{IC}_{50}$ values for the three technicians ranged from 3.6 to 4.3 $\mathrm{nM}$ with an overall\% CV of 22.7 for DHA (Figure 1) and 3.6 to $5.4 \mathrm{nM}$ (\% CV $=36.2$ overall) for AS. There was a statistically significant difference in $\mathrm{IC}_{50}$ values obtained from each of the three technicians for both DHA and AS ( $p<0.0001$ by Kruskal-Wallis test). A significant difference in median $\mathrm{IC}_{50}$ values was found between technician 1 and technician 2, as well as technician 1 and 3 $(p<0.0001$, Mann-Whitney $\mathrm{U}$ tests), but not between technician 2 and $3(p=0.84)$.

$\mathrm{IC}_{50}$ assays were conducted following parasite freezethaw for up to five cycles (Figure 1). Median $\mathrm{IC}_{50}$ values in five separate freeze/thaw experiments were 2.5-4.1 $\mathrm{nM}$ for DHA (\% CV $=27.8)$ and 2.7-3.9 $\mathrm{nM}$ for AS (\% $\mathrm{CV}=22$ ). To assess variability due to long-term parasite culture, $\mathrm{IC}_{50}$ values were evaluated monthly over a fivemonth period using a continuously growing W2 culture (Figure 1). During this time, median $\mathrm{IC}_{50}$ values

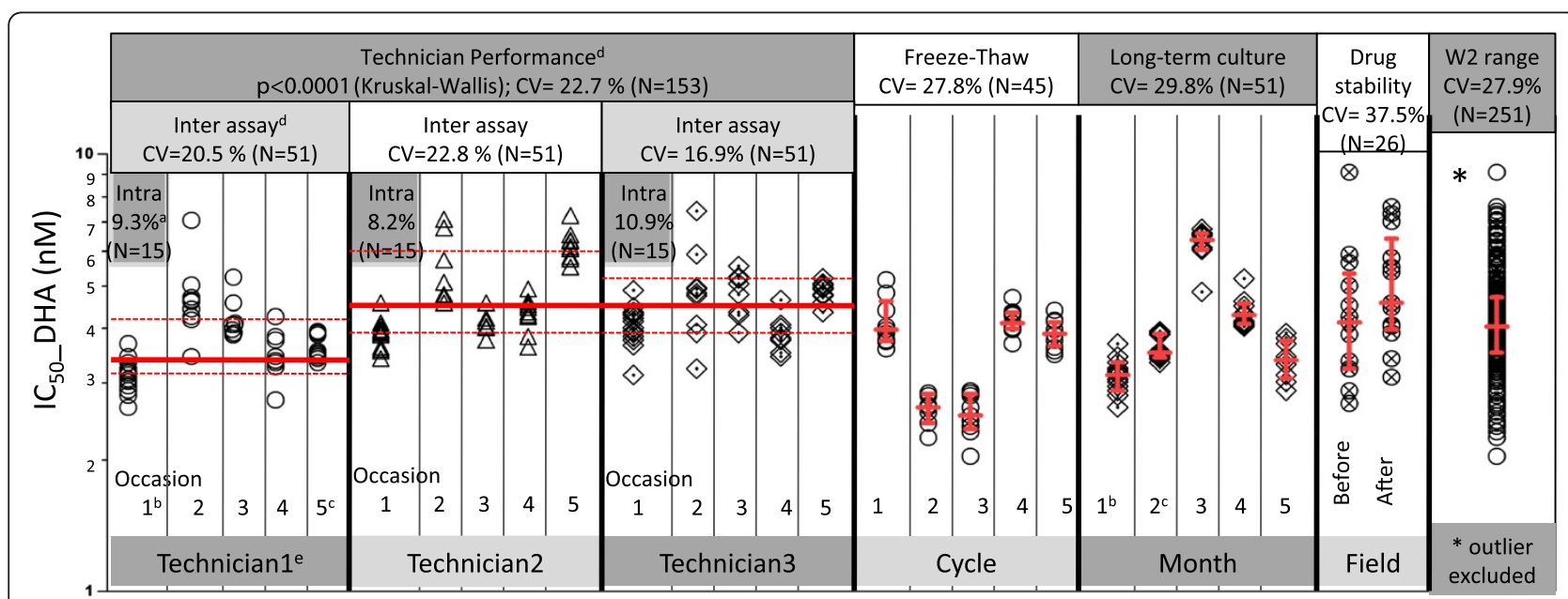

Figure 1 HRP-2 ELISA assay variability for the W2 Plasmodium falciparum parasite clone. Each data point represents an individual IC $C_{50}$ value obtained from triplicate columns on each of three or five drug-coated plates, generating nine or $15 \mathrm{IC}_{50}$ values per experiment/occasion. For the drug stability experiment under field conditions, ODs from duplicate columns were averaged to generate a single $I_{50}$ value for each plate, producing $26 I C_{50}$ values for 26 assays run. All individual IC $C_{50}$ values are presented in the "W2 Range" column. Red lines represent median ${ }^{I} C_{50} \mathrm{~S}$ and interquartile ranges. ${ }^{(a)}$ 'Intra-assay' variability is assessed by\% $\mathrm{CV}$ of IC $\mathrm{C}_{50}$ values within each HRP-2 assay conducted by a single technician on a single day. ${ }^{(b), ~(c) ~} I C_{50}$ values measured from the same experiment were analysed in both the intra/inter-assay variability and long-term culture variability. ${ }^{(d)}$ 'Inter-assay' variability was assessed by the $\% \mathrm{CV}$ of $I \mathrm{C}_{50}$ values among HRP-2 assays conducted on different days by the same technician, while technician performance was assessed by the difference in $I C_{50}$ values among technicians. ${ }^{(e)} I_{50}$ values obtained from technician 1 were significantly lower than those from technician 2 and 3. 
fluctuated between 3.0 and $6.4 \mathrm{nM}$ for DHA (\% CV= $29.8)$ and 3.0 and $6.7 \mathrm{nM}$ for $\mathrm{AS}(\% \mathrm{CV}=37.6)$.

The effects of drug-coated plate stability during transport to/from and storage at the field on $\mathrm{W} 2 \mathrm{IC}_{50}$ were evaluated, with 26 paired $\mathrm{IC}_{50}$ assays performed on 13 different drug-coated plate lots prior to transport, and upon return from remote field sites after several weeks (maximum two months) of storage on-site. Despite $\mathrm{IC}_{50}$ variability (\% CV) between individual plate lots for W2 with both DHA (\% CV=37.5) and AS (\% CV=49.2), there were no statistically significant differences in $\mathrm{IC}_{50}$ values obtained from plates before going and after returning from the field for either DHA (mean difference for DHA $-0.64 \mathrm{nM}$ for pairwise comparisons using the Wilcoxon matched-pair test; $\mathrm{p}=0.06$ ) or AS (difference of $0.08 \mathrm{nM} ; p=0.74$, see Figure 1 ).

When a total of $251 \mathrm{~W} 2 \mathrm{IC}_{50}$ values generated from all experiments were pooled, and outliers were excluded using Grubb's test, median $\mathrm{IC}_{50}$ of DHA was $4.1 \mathrm{nM}$ (IQR 3.5-4.7 nM), and AS was 4.2 nM (IQR 3.4-6.0 nM). The overall $\mathrm{IC}_{50}$ range was $2.0-7.6 \mathrm{nM}$ for DHA, and 2.0-9.4 $\mathrm{nM}$ for AS. Using the same plate lots, the median $\mathrm{IC}_{50}$ of CQ for the W2 clone was 297.4 nM (IQR 221.3$433.7 \mathrm{nM}$ ) and $21.3 \mathrm{nM}$ for MQ (IQR 18.3-31.7 nM) (Table 1). The W2 clone was resistant to CQ but susceptible to mefloquine when compared to other commonly used clones D6 and 3D7, while 3D7 was less artemisinin-sensitive than W2 and D6 (Table 2).

Quality control of drug-coated plates was evaluated by LC/MS of starting AS and DHA concentrations, measuring the highest drug concentration in the starting wells used to initiate serial dilutions. Variability was assessed over a period of six months using three different lots of drug-coated plates. Three plates per lot were randomly selected and a total of 27 starting drug concentrations (triplicate wells/plate) were measured (Figure 2). There was variation in starting drug concentration between plates for AS with $21.8 \% \mathrm{CV}$, and an overall median starting concentration of $14.7 \mathrm{ng} / \mathrm{mL}$ compared to a nominal target starting concentration of $20 \mathrm{ng} / \mathrm{mL}$ after addition of sample. For DHA, the median starting concentration was $11.9 \mathrm{ng} / \mathrm{mL}$ compared to a nominal value of $20 \mathrm{ng} /$

Table 1 Overall variation in $I_{50}$ values (nM) of DHA, AS, $M Q$ and $C Q$ against the $W 2$ clone measured from all validation experiments (Outlier $I C_{50}$ values were excluded)

\begin{tabular}{lllllll}
\hline Drug & $\mathbf{N}$ & $\begin{array}{l}\text { Geometric } \\
\text { mean }\end{array}$ & Median & Maximum & Minimum & IQR \\
\hline DHA & 250 & 4.1 & 4.1 & 7.6 & 2.0 & $3.5-4.7$ \\
AS & 250 & 4.4 & 4.2 & 9.4 & 2.0 & $3.4-6.0$ \\
MQ & 248 & 17.7 & 21.3 & 78.1 & 3.2 & $18.3-31.7$ \\
CQ & 251 & 304.5 & 297.4 & 779.1 & 116.3 & $221.3-433.7$ \\
\hline
\end{tabular}

Table 2 Median $\mathrm{IC}_{50}$ s (with interquartile ranges) of DHA, $A S, M Q$ and $C Q$ against W2, D6 and 3D7 clones in the HRP-2 assay ( $N=8$ each)

\begin{tabular}{lllll}
\hline $\mathbf{I C}_{\mathbf{5 0}}$ & DHA (nM) & AS (nM) & MQ (nM) & CQ (nM) \\
\hline W2 & $3.8(2.6-3.9)$ & $4.2(3.2-7.1)$ & $30.4(11.6-46.1)$ & $336.7(310.3-405.1)$ \\
D6 & $3.9(3.8-4.3)$ & $5.5(3.38-7.71)$ & $82.7(68.2-93.0)$ & $16.1(6.0-18.3)$ \\
3D7 & $6.0(4.6-7.3)$ & $10.2(5.2-11.4)$ & $66.3(60.8-76.1)$ & $21.9(10.2-28.3)$ \\
\hline
\end{tabular}

$\mathrm{mL}$ with a $13.3 \% \mathrm{CV}$ ( $\mathrm{n}=27$ for both drugs). Despite the differences between actual and nominal starting concentrations, there were no statistically significant differences in median starting concentrations between plate lots.

\section{Artemisinin susceptibility of field Plasmodium falciparum} isolates compared to the W2 clone

The $\mathrm{IC}_{50}$ values for DHA of field isolates from an artemisinin-resistant area in western Cambodia were compared to the W2 reference clone used for quality control on the same plate lots over a one-year period from August 2008 to August 2009 [17] (Figure 3). There were 12 lots of plates made in total for the study, with $\mathrm{IC}_{50}$ values generated for 125 volunteers, and there were no outlier $\mathrm{IC}_{50}$ values for the W2 parasite detected or excluded. Despite a broad susceptibility range of the field isolates, there was a significant increase in median $\mathrm{IC}_{50}$ for DHA ( $8.69 \mathrm{nM})$ compared to the W2 reference clone $(3.9 \mathrm{nM})$ both from patients with $100 \%$ parasite clearance time $\left(\mathrm{PCT}_{100}\right) \leq 72$ hours $(6.3 \mathrm{nM})$ and $>72$ hours $(9.6 \mathrm{nM}),(p<0.0001$, Mann-Whitney $U$ test $)$. Furthermore, the $\mathrm{IC}_{50}$ for DHA of field parasite isolates from patients with $\mathrm{PCT}_{100}>72$ hours was significantly higher

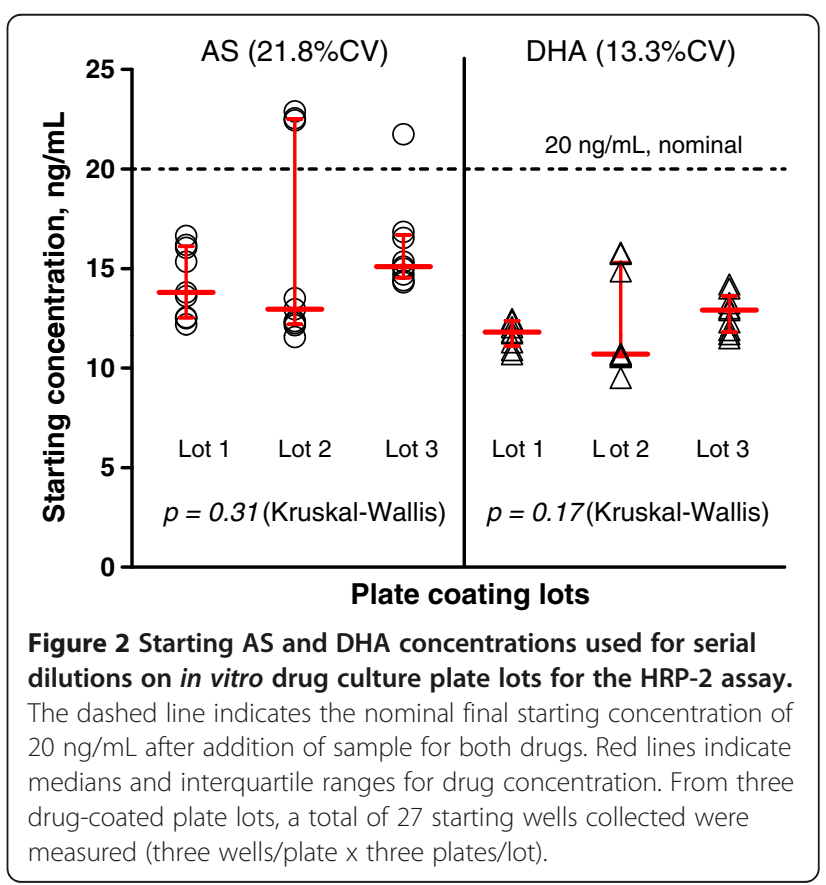




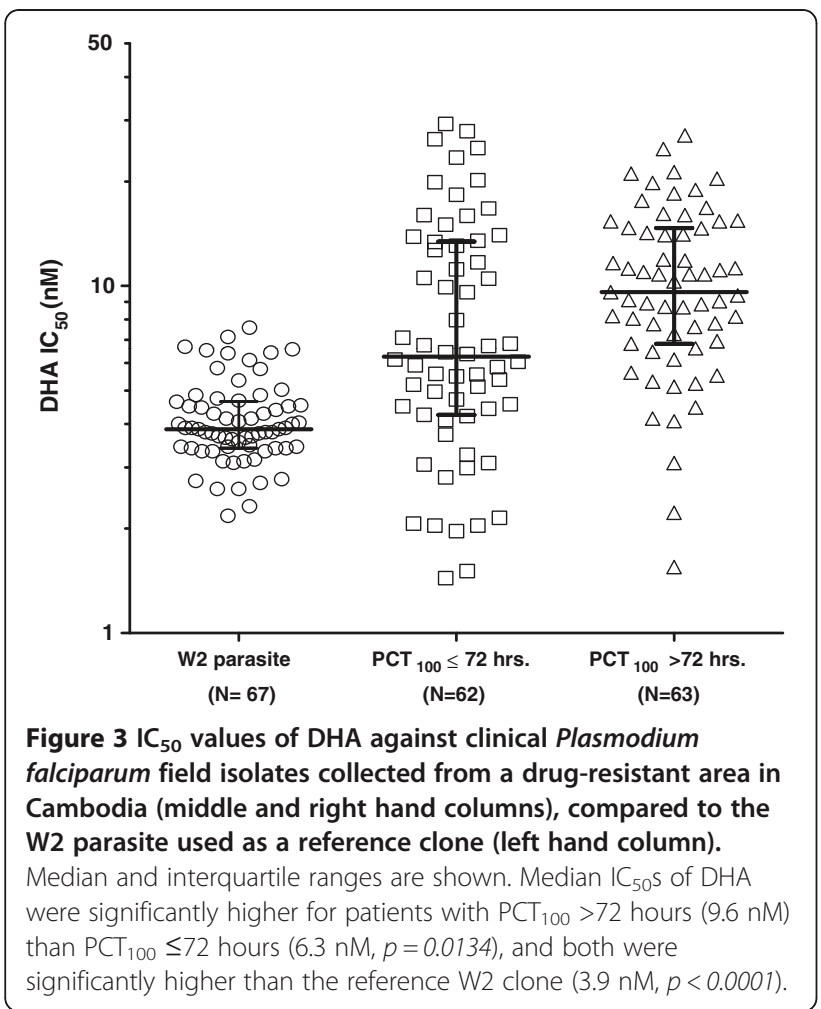

than $\mathrm{PCT}_{100} \leq 72$ hours $(p=0.0134)$. Similarly, median field isolate $\mathrm{IC}_{50} \mathrm{~S}$ for $\mathrm{AS}$ were significantly higher than those for the W2 clone $(p<0.0001$, Mann-Whitney $U$ test), and there were significant differences between PCTs greater than or less than 72 hours $(6.0 \mathrm{nM}$ vs 5.4 $\mathrm{nM}, p=0.039$ ).

\section{Discussion}

The value of using an artemisinin-susceptible W2 clone to control for the inherent variability in the HRP-2 in vitro assay was demonstrated here, particularly with field isolates, defining a range for drug susceptibility assay performance. By comparing field isolates with a reference clone used for the same plate lots, a clear determination of a reduction in drug susceptibility in an area of reported drug resistance in Cambodia can be attained. This approach has significant public health utility, allowing meaningful comparisons of field isolates populations, and controlling for variability in assay conditions. Although individual or even collective $\mathrm{IC}_{50}$ values may offer little in predicting the onset of drug resistance in a community due to wide variability and differences in assay methods and conditions, comparison with a well-characterized clone mitigated some of these limitations on assay interpretation. The use of a reference clone to directly measure reproducibility of $\mathrm{IC}_{50}$ values on plates used to assess field isolates may be particularly valuable in accounting for variability due to technique, providing more meaningful inter-laboratory and multi-site surveillance comparisons.

The inherent variability of the HRP-2 ELISA-based $\mathrm{IC}_{50}$ assay was quantified and variation in drug concentrations between different plates was found to be an important source of assay variability, confirmed by LC/MS analysis of plate concentrations. While a significant difference in starting drug concentrations between plate-coating lots was not observed, actual drug concentrations recovered from the plates by LC/MS were generally below nominal concentrations, indicating that final $\mathrm{IC}_{50}$ may have been overestimated. Greater variation in AS plate concentrations observed compared to DHA may explain somewhat higher variability in $\mathrm{AS} \mathrm{IC}_{50}$ values compared to DHA. Unlike DHA, the variation seen could be explained by the fact that AS (an esterified butanedioic acid) is readily hydrolyzed to DHA and succinic acid in aqueous solution. Inherent assay variability provides additional impetus to standardize methods wherever possible, and index results to a reference clone. Methods to improve the reproducibility and precision of drug dilutions (e g, use of a pipetting robot, improved stabilizing techniques, or plates with materials that drug substance is unlikely to adhere to) may have the greatest impact on further improving assay reliability. There was significant day-to-day inter-assay IC50 variability for individual technicians (\% $\mathrm{CV}>30$ for $\mathrm{AS}$ ), as well as differences in performance between technicians. Some degree of difference attributable to manual performance of laboratory techniques is expected. Understanding this variability helps to further define the performance range of this assay, and further supports interpretation of field isolate values.

Freeze/thaw cycles, and long-term culture of the W2 clone were less important sources of assay variability, as $\mathrm{IC}_{50}$ values generated during culture time/freeze-thaw cycles fluctuated within the assay performance range. Despite an increase in $\mathrm{IC}_{50}$ values at month 3 and 4 , variability was no greater than that seen between assays performed by the same technician on different days (inter-assay variability), and values at month 5 returned to baseline, suggesting that there were no time-dependent changes in $\mathrm{W} 2 \mathrm{IC}_{50}$ values arising from long-term continuous culture. Transport and storage of drug plates in field conditions did not account for substantial variability, with no difference in $\mathrm{W} 2 \mathrm{IC}_{50}$ values obtained before and after transport to the field, supporting the utility of the HRP-2 method at remote field sites. Unmeasured variability in assay conditions and parasite characteristics may also have contributed. Understanding the inherent variability of the assay, and defining performance ranges of reference parasite clones, are important for laboratories conducting drug susceptibility assays on field isolates.

A reference clone may further be useful in overcoming issues of sampling bias originating from two sources in in vitro/ex vivo susceptibility studies. Samples reported 
from in vitro/ex vivo clinical isolate studies are generally derived from clinical trials or dedicated parasite sampling studies. However, in both cases, systematic sampling methods (e g, randomized household cluster surveys) are rarely employed, instead relying on convenience sampling from particular clinics or communities, or retrospective reviews of sample collection efforts from multiple sites and/or laboratories. Recovery of malaria isolates from culture, and interpretability of parasite growth curves are other potential sources of sampling bias, with the proportion of evaluable samples as low as $50-60 \%$ in some cases. Low parasitaemia samples are particularly problematic, and the effects on point estimates of 'resistance' can be problematic due to the unmeasurable impact of non-recovery on population values. By establishing a susceptibility baseline, comparison with a reference clone mitigates these uncertainties to some extent, facilitating sample comparisons at the population level.

While the W2 clone showed similar trends against W2, D6 and 3D7 in our hands to those previously reported in the HRP-2 assay, the values were not identical, underscoring the need for standardization within and among laboratories. Each in vitro assay system has limitations. Because of its high sensitivity, HRP-2 is used as a parasite detection method in several rapid diagnostic test kits [24], and has even been advocated for use in a salivary detection test [25]. HRP-2 is a by-product of parasite metabolism that persists in blood following malaria infection and treatment, making it a poor prognostic indicator. Differences in metabolic conditions during the culture process could potentially confound the interpretation of in vitro assay results [26]. The HRP-2 in vitro drug sensitivity method presented here has been advocated in populations with low transmission rates, low or fluctuating parasite densities, and chronic infections, and is considered to be acceptable for use in Southeast Asia for these reasons [5,27]. Some have suggested that the SYBR Green I method's specificity in whole blood may be confounded by the presence of human DNA, limiting its utility in clinical isolates [28]. However, a recent report from Kenya found SYBR Green I to be a sensitive, cost-effective method for field use, and $\mathrm{IC}_{50}$ values compared well with historic parasite data using the tritiated hypoxanthine method [12]. Even with the longaccepted "gold standard" hypoxanthine method, wide variability in field isolate values has been reported, most recently in a published review of in vitro data collected from drug efficacy trials in Cambodia over seven years. While the large sample size allowed detection of discernible differences in drug susceptibility between specimens collected in the eastern and western portions of the country, such extensive collection efforts may not be feasible in all settings [29].
The reference clone provides a higher level of assurance in the validity and comparability of smaller data sets, and allows for monitoring of trends over shorter periods to support timely public health action, including shifts in drug treatment policy. Comparing changes in field isolate $\mathrm{IC}_{50} \mathrm{~s}$ indexed to a well-characterized reference clone that demonstrates within-laboratory reproducibility is recommended. For an assay to have public health utility, the choice of methodology is less important than demonstrated experience with the system, use of a well-characterized reference clone, and most importantly, establishment of reproducible methods.

\section{Conclusions}

The use of standardized $P$. falciparum reference clones to provide context for variability among several assay systems is a key in harmonizing regional laboratories for in vitro/ex vivo drug susceptibility monitoring. Quantifying inherent assay variability and establishing a drug susceptibility range of the reference $P$. falciparum clone permitted meaningful data comparisons and improved the interpretability of field isolate susceptibility.

\section{Competing interests}

The authors declare that they have no competing interests. The views expressed in this article are those of the author(s) and do not reflect the official policy of the Department of the Army, Department of Defense, or the US Government. All human use research received the required ethical approvals from the appropriate authorities.

\section{Authors' contributions}

Study design: WR, KS, SDT. Conducted experiments, collected and analysed data: WR, SC, SDT, PT, KY, PC, YS, DB, CL, KS. Data interpretation, manuscript preparation: SC, PT, DSW, WR, DLS. Project oversight: SDT, MMF, KS, HN, DS and DLS. All authors read and approved the final manuscript.

\section{Acknowledgements}

This work was supported by funding provided by the DoD Global Emerging Infectious Surveillance (GEIS) and the Medicines for Malaria Venture (MMV). We thank Dr.William Ellis at the Walter Reed Army Institute of Research (WRAIR) for providing us with drug compounds, and Ms Somporn Krasaesub for advice on statistical analysis. In addition, we thank Ms Piyaporn Saingam, Ms Siratchana Sundrakes, Ms Raveewan Siripokasubkul and Ms Roongnapha Apinan for technical assistance. Dr Sea Darapiseth, and Messrs Sittidech

Surasri, Worachet Kuntawunginn, Theera Wimonwattrawatee, Montri Arsanok, and Ms Monticha Kongthaisong conducted the clinical study and cultured isolates in the field.

\section{Author details}

'Department of Immunology and Medicine, US Army Medical Corps, Armed Forces Research Institute of Medical Sciences (USAMC-AFRIMS), Bangkok, Thailand. ${ }^{2}$ Armed Forces Health Surveillance Center, Silver Spring, MD, USA. ${ }^{3}$ The National Center for Parasitology, Entomology and Malaria Control (CNM), Ministry of Health, Phnom Penh, Cambodia. ${ }^{4}$ Medical University of Vienna, Vienna, Austria.

Received: 21 June 2012 Accepted: 28 August 2012

Published: 13 September 2012

\section{References}

1. Dondorp AM, Nosten F, Yi P, Das D, Phyo AP, Tarning J, Lwin KM, Ariey F, Hanpithakpong W, Lee SJ, Ringwald P, Silamut K, Imwong M, Chotivanich K, Lim P, Herdman T, Sam An S, Yeung S, Singhasivanon P, Day NPJ, 
Lindegardh N, Socheat D, White NJ: Artemisinin resistance in Plasmodium falciparum malaria. N Engl J Med 2009, 361:455-467.

2. Noedl H, Se Y, Schaecher K, Smith BL, Socheat D, Fukuda MM: Evidence of artemisinin-resistant malaria in western Cambodia. N Engl J Med 2008, 359:2619-2620.

3. Noedl H, Attlmayr B, Wernsdorfer WH, Kollaritsch H, Miller RS: A histidinerich protein 2-based malaria drug sensitivity assay for field use. Am J Trop Med Hyg 2004, 71:711-714.

4. Noedl H, Bronnert J, Yingyuen K, Attlmayr B, Kollaritsch H, Fukuda M: Simple histidine-rich protein 2 double-site sandwich enzyme-linked immunosorbent assay for use in malaria drug sensitivity testing. Antimicrob Agents Chemother 2005, 49:3575-3577.

5. Noedl $H$, Wernsdorfer WH, Miller RS, Wongsrichanalai C: Histidine-rich protein II: a novel approach to malaria drug sensitivity testing. Antimicrob Agents Chemother 2002, 46:1658-1664.

6. Desjardins RE, Canfield CJ, Haynes JD, Chulay JD: Quantitative assessment of antimalarial activity in vitro by a semiautomated microdilution technique. Antimicrob Agents Chemother 1979, 16:710-718.

7. Petersen $\mathrm{E}: 3 \mathrm{H}$-hypoxanthine incorporation into fresh and stored blood: implications for resistance determination in P. falciparum malaria. Ann Trop Med Parasitol 1986, 80:251-252.

8. Co EM, Dennull RA, Reinbold DD, Waters NC, Johnson JD: Assessment of malaria in vitro drug combination screening and mixed-strain infections using the malaria Sybr green I-based fluorescence assay. Antimicrob Agents Chemother 2009, 53:2557-2563.

9. Rason MA, Randriantsoa T, Andrianantenaina H, Ratsimbasoa A, Menard D: Performance and reliability of the SYBR Green I based assay for the routine monitoring of susceptibility of Plasmodium falciparum clinical isolates. Trans R Soc Trop Med Hyg 2008, 102:346-351.

10. Johnson JD, Dennull RA, Gerena L, Lopez-Sanchez M, Roncal NE, Waters NC: Assessment and continued validation of the malaria SYBR green I-based fluorescence assay for use in malaria drug screening. Antimicrob Agents Chemother 2007, 51:1926-1933.

11. Bacon DJ, Latour C, Lucas C, Colina O, Ringwald P, Picot S: Comparison of a SYBR green I-based assay with a histidine-rich protein II enzyme-linked immunosorbent assay for in vitro antimalarial drug efficacy testing and application to clinical isolates. Antimicrob Agents Chemother 2007, 51:1172-1178

12. Akala HM, Eyase FL, Cheruiyot AC, Omondi AA, Ogutu BR, Waters NC, Johnson JD, Polhemus ME, Schnabel DC, Walsh DS: Antimalarial drug sensitivity profile of western Kenya Plasmodium falciparum field isolates determined by a SYBR Green I in vitro assay and molecular analysis. Am J Trop Med Hyg 2011, 85:34-41.

13. Bacon DJ, Jambou R, Fandeur T, Le Bras J, Wongsrichanalai C, Fukuda MM, Ringwald P, Sibley CH, Kyle DE: World Antimalarial Resistance Network (WARN) II: in vitro antimalarial drug susceptibility. Malar J 2007, 6:120.

14. Noedl H, Faiz MA, Yunus EB, Rahman MR, Hossain MA, Samad R, Miller RS, Pang LW, Wongsrichanalai C: Drug-resistant malaria in Bangladesh: an in vitro assessment. Am J Trop Med Hyg 2003, 68:140-142.

15. Wein S, Maynadier M, Tran Van Ba C, Cerdan R, Peyrottes S, Fraisse L, Vial H: Reliability of antimalarial sensitivity tests depends on drug mechanisms of action. J Clin Microbiol 2010, 48:1651-1660.

16. Noedl H, Se Y, Sriwichai S, Schaecher $K$, Teja-Isavadharm P, Smith B, Rutvisuttinunt W, Bethell D, Surasri S, Fukuda MM, Socheat D, Chan Thap L: Artemisinin resistance in Cambodia: a clinical trial designed to address an emerging problem in Southeast Asia. Clin Infect Dis 2010, 51:e82-e89.

17. Bethell D, Se Y, Lon C, Tyner S, Saunders D, Sriwichai S, Darapiseth S, TejaIsavadharm P, Khemawoot P, Schaecher K, Ruttvisutinunt W, Lin J, Kuntawungin W, Gosi P, Timmermans A, Smith B, Socheat D, Fukuda MM: Artesunate dose escalation for the treatment of uncomplicated malaria in a region of reported artemisinin resistance: a randomized clinical trial. PLoS One 2011, 6:e19283.

18. Chaijaroenkul W, Bangchang KN, Mungthin M, Ward SA: In vitro antimalarial drug susceptibility in Thai border areas from 1998-2003. Malar J 2005, 4:37.

19. Trager $W$, Jensen JB: Human malaria parasites in continuous culture. Science 1976, 193:673-675.

20. Lambros C, Vanderberg JP: Synchronization of Plasmodium falciparum erythrocytic stages in culture. J Parasitol 1979, 65:418-420.

21. Teja-Isavadharm $P$, Siriyanonda D, Siripokasupkul R, Apinan $R$, Chanarat N, Lim A, Wannaying S, Saunders D, Fukuda MM, Miller RS, Weina PJ, Meléndez
V: A simplified liquid chromatography-mass spectrometry assay for artesunate and dihydroartemisinin, its metabolite, in human plasma. Molecules 2010, 15:8747-8768.

22. Le Nagard $H$, Vincent $C$, Mentre $F$, Le Bras J: Online analysis of in vitro resistance to antimalarial drugs through nonlinear regression. Comput Methods Programs Biomed 2011, 104:10-18.

23. Kaddouri H, Nakache S, Houze S, Mentre F, Le Bras J: Assessment of the drug susceptibility of Plasmodium falciparum clinical isolates from africa by using a Plasmodium lactate dehydrogenase immunodetection assay and an inhibitory maximum effect model for precise measurement of the 50-percent inhibitory concentration. Antimicrob Agents Chemother 2006, 50:3343-3349.

24. Bell DR, Wilson DW, Martin LB: False-positive results of a Plasmodium falciparum histidine-rich protein 2-detecting malaria rapid diagnostic test due to high sensitivity in a community with fluctuating low parasite density. Am J Trop Med Hyg 2005, 73:199-203.

25. Wilson NO, Adjei AA, Anderson W, Baidoo S, Stiles JK: Detection of Plasmodium falciparum histidine-rich protein II in saliva of malaria patients. Am J Trop Med Hyg 2008, 78:733-735.

26. Tjitra E, Suprianto S, Dyer ME, Currie BJ, Anstey NM: Detection of histidine rich protein 2 and panmalarial ICT Malaria Pf/Pv test antigens after chloroquine treatment of uncomplicated falciparum malaria does not reliably predict treatment outcome in eastern Indonesia. Am J Trop Med Hyg 2001, 65:593-598.

27. Noedl $H$, Wongsrichanalai $C$, Wernsdorfer WH: Malaria drug-sensitivity testing: new assays, new perspectives. Trends Parasitol 2003, 19:175-181.

28. Vossen MG, Pferschy S, Chiba P, Noedl H: The SYBR green I malaria drug sensitivity assay: performance in low parasitemia samples. Am J Trop Med Hyg 2010, 82:398-401.

29. Lim P, Wongsrichanalai C, Chim P, Khim N, Kim S, Chy S, Sem R, Nhem S, Yi P, Duong S, Mey Bouth D, Genton B, Beck H, Gobert JG, Rogers WO, Coppee JY, Fandeur T, Mercereau-Puijalon O, Ringwald P, Le Bras J, Ariey F: Decreased in vitro susceptibility of Plasmodium falciparum isolates to artesunate, mefloquine, chloroquine, and quinine in Cambodia from 2001 to 2007. Antimicrob Agents Chemother 2010, 54:2135-2142.

doi:10.1186/1475-2875-11-325

Cite this article as: Rutvisuttinunt et al:: Optimizing the HRP-2 in vitro malaria drug susceptibility assay using a reference clone to improve comparisons of Plasmodium falciparum field isolates. Malaria Journal 2012 11:325.

\section{Submit your next manuscript to BioMed Central and take full advantage of:}

- Convenient online submission

- Thorough peer review

- No space constraints or color figure charges

- Immediate publication on acceptance

- Inclusion in PubMed, CAS, Scopus and Google Scholar

- Research which is freely available for redistribution

Submit your manuscript at www.biomedcentral.com/submit
C) Biomed Central 